PSICOLOGIA. Vol. XII. No 1.1994

\title{
NUEVAS INTERPRETACIONES DE LA PSICOLOGIA DEL DESARROLLO CON RELACION A LOS DETERMINANTES DE LA CONDUCTA
}

Cecilia Thorne ${ }^{1}$

El artículo presenta dos posiciones actuales que buscan explicar el desarrollo humano desde perspectivas diferentes. Por un lado, se presenta la posición de Scarr acerca de los efectos de los genotipos sobre el ambiente, donde el peso de la interpretación está dado en los aspectos hereditarios. Por otro lado, la teoría ecológica sustentada por Bronfenbrenner que define al desarrollo humano como una interacción entre la persona en desarrollo y su medio ambiente. La autora discute algunos aspectos de ambas posiciones en los que sería importante profundizar para prevenir efectos negativos y tener una mejor comprensión del desarrollo del niño, en países en vías de desarrollo.

Palabras claves: desarrollo del niño, herencia, medio ambiente, teoría ecológica.

New interpretations of developmental psychology regarding the determinants of conduct.

Two current positions in the field of human development are presented. On the one hand, Scarr's theory about the effects of genotype on environment is discussed. On the other hand, the ecological theory of Bronfenbrenner, which describes human development as an interaction between the developing person and his/her environment. The author discusses some aspects of both positions that need further study in order to prevent negative effects and have a better understanding of child development, in third world countries.

Key words: child development, heredity, environment, ecological theory.

1. Profesora Principal de la Sección de Psicología del Departamento de Humanidades de la Pontificia Universidad Católica del Perú. Apartado 1761, Lima 100-Perú; Internet: cthorne@pucp.edu.pe. Obtuvo el grado de doctor en psicología en la Universidad Católica de Nijmegen (Holanda), y realizó sus estudios de psicología en la Universidad de París V (Francia). Ha realizado investigaciones sobre el aprendizaje de la lectura y la escritura en niños de primer grado en el Perú, sobre evaluación intelectual y educacional y otros temas de psicología y educación. Es Directora de la Revista de Psicología de la P.U.C.P. y autora de múltiples artículos. Es miembro fundador del Colegio de Psicólogos del Perú, así como miembro de varias sociedades científicas internacionales. 



\section{Introducción}

El Perú es un país joven donde casi el $40 \%$ de la población tiene por debajo de 15 años. Es por ello que comprender el desarrollo de nuestros nińos debe ser una tarea fundamental de la Psicología en nuestro medio. Si hacemos un análisis de los trabajos realizados, por ejemplo, en el campo de pruebas psicológicas más del $50 \%$ han sido hecho con muestras de niños (Thorne, Delgado y Escurra, 1993).

Los países en vías de desarrollo deben buscar modos propios de interpretación acerca del desarrollo del individuo. Estos tienen características tales que los modelos de países desarrollados no siempre se ajustan a una comprensión adecuada del desarrollo de los niños de paises en vías de desarrollo.

En nuestro medio, existen algunos esfuerzos como los trabajos de González (1992), Majluf (1993), y Panez (1989). Sin embargo, y a pesar de los trabajos realizados, pienso que no tenemos una idea global de cómo interpretar los diferentes hallazgos de las investigaciones y menos aún tenemos una comprensión del interjuego o de la correlación entre la herencia y el contexto en que crece el niño y cómo esto afecta el desarrollo del niño.

Una psicología del desarrollo moderna, según Hoffman et al. (1988) tiene entre sus objetivos lograr un conjunto de metas que son:

1. Describir los cambios en el crecimiento físico, en el pensamiento y en personalidad que se dan con la edad y la experiencia.

2. Comparar personas de diferente bagaje cultural, con historias biológicas y de crianza diferente. 
3. Explicar los cambios evolutivos y su secuencia de acuerdo a principios, reglas, teorías y mecanismos.

4. Predecir patrones de desarrollo. Esto permite controlarlo y mejorar situaciones en aquellos casos en los que el desarrollo se ve afectado y hasta prevenir otros problemas de desarrollo. La idea es que los individuos desarrollen sus capacidades lo mejor posible y tengan una vida mejor.

5. Relacionar los hallazgos de la Psicología del Desarrollo con el trabajo de otras disciplinas, para que la información sea útil a educadores, padres, terapéutas y terapistas, trabajadores sociales y científicos.

Hasta no hace mucho tiempo, la mayoría de psicólogos del desarrollo creían que el mayor objetivo de su investigación era descubrir las leyes eternas acerca del desarrollo humano. Unos tenían un enfoque nomotético, buscando leyes universales acerca de la secuencia y contexto del desarrollo. Otros, un grupo más pequeño centraba su investigación en las variaciones individuales o en patrones ideográficos, es decir patrones únicos del individuo (Scarr, 1992). Pienso que en nuestro medio aún no se ha superado esta posición, buscándose sobre todo leyes universales acerca de la secuencia del desarrollo.

A través de este artículo intentamos explicar, a la luz de dos orientaciones teóricas, la interpretación de los determinantes del desarrollo con el objeto de tener una aproximación más flexible que nos permita una mejor comprensión del niño en su contexto. Así podremos no sólo describir, comparar, explicar, predecir y relacionar mejor el desarrollo del nińo, sino sobre todo intervenir para prevenir problemas. Nos proponemos exponer qué dicen en la actualidad las posiciones biológicas y ambientalistas y qué nuevas interpretaciones y explicaciones se dan con relación a berencia y medio ambiente y plantearnos algunos puntos que son importantes para la mejor comprensión del desarrollo del niño. Por un lado, presentaremos la posición de Scarr acerca de los efectos del genotipo $\rightarrow$ ambiente en el desarrollo; por otro lado, la posición de la teoría ecológica que define al desarrollo como una interacción entre la persona en desarrollo y su medio ambiente. 


\section{Los Determinantes del Desarrollo}

Cuando nos referimos a los determinantes del desarrollo estamos aludiendo a aquello que origina la conducta. ¿Dónde se origina la conducta? Continúa la eterna disputa acerca de los orígenes del desarrollo y si bien las discusiones siguen oscilando entre dos puntos fundamentales herencia (Scarr y Weinberg, 1983; Scarr y Ricciuti, 1991, Scarr, 1992) y medio ambiente (Brofenbrenner, 1979,1986; Gordon y Armour-Thomas, 1991; Okagaki y Sternberg, 1991, Pollitt, 1974, 1991) el modo en que se trata el tema ha cambiado del cuánto al cómo buscándose más una comprensión del desarrollo donde se reconoce que este desarrollo no es producto exclusivamente de uno u otro. Es decir, que existe un consenso en que la conducta depende tanto del patrimonio hereditario de la persona como de su medio ambiente. Los progresos se han dado en el modo de interpretación de ambos determinantes y cómo estos nos permiten una mejor explicación del desarrollo del individuo.

\section{La teoría de los efectos del genotipo sobre el ambiente}

La pregunta que ha motivado la investigación de Scarr en los últimos 25 años es "¿Cómo los organismos y los ambientes se combinan para producir el desarrollo humano y las muchas variaciones sobre el tema?" El punto de partida para explicar el desarrollo humano está dado por los efectos de los genotipos sobre el ambiente. Sin dejar de lado el concepto de ambiente, la interpretación está dada en los genotipos.

Los avances de las neurociencias y en particular la biogenética han puesto de manifiesto la influencia de los genes en nuestra conducta todo a lo largo del ciclo vital. En otras palabras, en los diferentes momentos del desarrollo, los genes "se prenden" o se activan produciendo sustancias dentro del cuerpo que crean nuevas estructuras que regulan sus funciones o mantienen sus estados. Este es un cambio fundamental, ya que lo genético actúa a lo largo de todo el ciclo vital de la persona y no únicamente en los primeros años del desarrollo.

Scarr (1992) propone que es posible incorporar tanto el desarrollo típico y las variaciones individuales de los patrones característicos en nuevas 
teorías que describen y explican el desarrollo humano, tanto típicamente humano como único.

Los estudios de Scarr y Weinberg (1983) en niños adoptados muestran evidencias de fuentes genéticas de variabilidad para las características estudiadas desde la temprana infancia hasta el fin de la crianza. Los estudios realizados muestran, por un lado, que los niños más pequeños más allá del parentesco genético se parecen unos a los otros intelectualmente porque comparten un ambiente similar. Por otro lado, los adolescentes se parecen entre ellos sólo si comparten genes. $\mathrm{La}$ interpretación es que los jóvenes escapan a las influencias de la familia y están más libres para seleccionar sus propios ambientes. Las influencias parentales se ven atenuadas por una mezcla más variada de experiencias adolescentes.

Estos estudios dan evidencia de la maleabilidad del desarrollo que es interpretada como la sensibilidad de los genotipos a las diferencias ambientales. En otras palabras, cuando los ambientes son positivos, los niños adoptados responderán positivamente siendo esto un indicador de maleabilidad. La maleabilidad, sin embargo, no significa que dado un mismo ambiente todos terminaremos igual. Existe un límite en esta maleabilidad, dada por los genes.

De acuerdo a datos de investigaciones recogidas, en una gran variedad de rasgos, que incluyen medidas de inteligencias, habilidades cognitivas específicas, personalidad y psicopatología, tanto en norteamérica como en europa, hay tanta variación dentro de una familia como entre familias. Ser criado en una familia o en otra tiene poca o casi ninguna diferencia en el desarrollo personal e intelectual del niño. Estos datos sugieren que los ambientes que muchos padres proveen para sus hijos tienen pocos efectos diferenciales en sus descendientes.

Scarr propone que cada nińo construye una realidad a partir de las oportunidades que brinda el ambiente de crianza y la realidad construida tiene una influencia considerable en las variaciones entre niños y diferencias en su vida adulta.

Dada las contradicciones en las distintas teorías o puntos de vista psicológicos como el cognitivo, el clínico, el social o el de la personalidad o cultural en como las personas son influenciadas por sus ambientes y como 
construyen sus experiencias a partir de esos ambientes, Scarr propone para solucionar estas diferencias es importante incorporar el concepto de "Ambiente Promedio Esperable". LeVine, (Scarr, 1992) señala tres componentes que describen organismos normales en ambientes normales. Estos son:

1. Preadaptación - Los infantes y los niños están preadaptados por la herencia genética de la especie para responder a un rango específico de oportunidades ambientales para estimulación y adquisición de conocimientos.

2. Variación - Dentro del rango genético específico de ambientes normales, existe una variedad de patrones de estimulación que pueden actuar para promover patrones normales de desarrollo. Amplias variaciones en el los ambientes dentro de este rango normal presenta oportunidades "funcionalmente equivalentes" para las personas que les permite construir sus propias experiencias.

3. Límites - Los ambientes que caen fuera de confines normales de la especie no promoverán patrones normales de desarrollo. Este concepto es capital para comprender el desarrollo y para prevenir problemas o dificultades en el desarrollo del individuo. Esto quiere decir que mientras el niño se encuentre dentro de un ambiente promedio que no salga de determinados límites, el desarrollo podrá darse normalmente. Lo importante es determinar a partir de qué momento un ambiente no es promedio esperable. En un país como el Perú donde hay un número bastante elevado de personas que se encuentra en un estado de pobreza extrema, habría que determinar a partir de qué grado de pobreza el niño no va a evolucionar normalmente.

¿Cómo las personas pueden crear su propia experiencia? Scarr propone que es mejor hablar de correlaciones genotipo $\rightarrow$ ambiente, más que interacciones gene-ambiente. Las oportunidades ambientales son tomadas por algunos individuos y no por otros, dependiendo de sus características individuales. Propone que las personas crean su propio ambiente de tres maneras:

- En primer lugar, los genes de los niños están necesariamente correlacionados con sus ambientes porque los padres proveen ambos, 
de tal modo que sus experiencias están construidas a partir de oportunidades que correlacionan positivamente con sus características personales. Por ejemplo, a un padre que le gusta leer tendrá más libros o estará suscrito a revistas. Si los padres tienen problemas de lectura, probablemente no leerán y sus hijos también tendrán problemas o no serán tan lectores porque no han tenido un ambiente que los estimule. Por lo tanto, se dice que las habilidades de los padres en lectura están correlacionadas postitivamente con las habilidades en lectura de sus hijos y con los ambientes que sus padres les brindan. Una efecto positivo genotipo-ambiente.

- En segundo lugar, las personas despiertan en los otros respuestas que están correlacionadas con sus propias características en los diferentes momentos del desarrollo. Estas respuestas tienen efectos profundos en la imagen de la persona y en la autoestima. Niños sonrientes y alegres despiertan interacciones positivas de los padres y otros adultos y tendrán impresiones positivas del mundo social. Niños de familias pobres que son más inteligentes van a tener mayor atención y estimulación de sus maestros. Los adultos que son fisicamente más atractivos tienen mayores citas y parejas y posiblemente los contratan para más trabajos.

- Por último, las personas seleccionan activamente ambientes que están correlacionados con sus intereses, talentos y características de personalidad.

De todo esto se desprenden tres proposiciones en la teoría de los efectos del genotipo ambiente:

1. Hay tres tipos de genotipo: pasivo, evocativo y activo.

2. El simetría o equilibrio de los efectos genotipo ambiente cambia de pasivo a activo, a medida que los niños salen de su familia para hacer sus propias elecciones de intereses y actividades. Las personas escogen ambientes ocupacionales que correlacionan con sus preferencias personales para interacciones sociales o trabajo solitario, para trabajo independiente o supervisado, etc.

3. Las diferencias genéticas se hacen más importantes a lo largo del desarrollo, a medida que las personas construyen su propio ambiente. 
Finalmente, los estudios de familia demuestran que los diferentes métodos de crianza, clase social e ingresos tienen pocos efectos sobre la inteligencia, intereses y personalidad. Esto no quiere decir que no tenga efectos en la autoestima, motivación o ambición. Lo que estos estudios están demostrando es que los padres no pueden hacer con sus hijos lo que quieren como lo proponía Watson en 1925 (Biehler, 1980).

Denme una docena de niños sanos, bien formados, y mi propio mundo específico para educarlos y yo garantizo que tomo uno al azar y le entreno para que sea un especialista de cualquier clase que escoja yo -médico, abogado, artista, jefe de empresa, y también, sí hasta mendigo y ladrón-independientemente de su talento, inclinación, tendencia, aptitudes, vocaciones y raza de sus antepasados.

La evolución no ha dejado el desarrollo de la especie a la merced de los ambientes. En realidad los humanos somos lo suficientemente fuertes y capaces de adaptarnos a una amplia gama de circunstancias, indicando esto que no se puede intervenir fácilmente. Sólo se puede intervenir cuando los ambientes se encuentran fuera del rango normal.

\section{La ecología del desarrollo humano}

Esta teoría se origina en los trabajos de Bronfenbrenner $(1979,1986)$, quien a su vez toma algunos conceptos de la teoría del campo psicológico de Lewin. La aproximación hacia el desarrollo del individuo se hace a partir de una nueva concepción de ambiente, descartándose la idea de un ambiente estático que tiene influencia en la conducta. El desarrollo es definido como un cambio duradero en el modo en que la persona percibe y trata su ambiente.

La ecología del desarrollo humano incluye el estudio científico de la acomodación mutua y progresiva entre un ser humano activo y en crecimiento y las propiedades de cambios de los escenarios inmediatos en que vive la persona en desarrollo, a medida que estos procesos se ven afectados por relaciones entre estos escenarios, y por un contexto más amplio en que estos escenarios están implantados. 
Lo importante en esta postura es que la persona no es vista como una tábula rasa en la cual el ambiente hace un impacto. Se le percibe, más bien, como una entidad dinámica que progresivamente se mueve y reestructura su medio. La interacción entre la persona y el medio es bidireccional y recíproca. El ambiente definido como importante para el desarrollo no está limitado a un escenario único e inmediato. Este se extiende a incorporar interconexiones entre los escenarios, así como influencias externas que emanan de ambientes más amplios. El ambiente ecológico es concebido topológicamente como un arreglo concéntrico de estructuras cada una contenida dentro de la otra. Estas estructuras son el micro-meso-exo- y macrosistema.

En el nivel más interno está el microsistema que es el lugar inmediato que contiene a la persona en desarrollo. Es un patrón de desarrollo de actividades, roles e interrelaciones personales que experimenta la persona en desarrollo. Este puede ser el hogar o el salón de clase. Lo importante es de qué modo es experimentado o percibido por la persona.

El siguiente paso significa mirar más allá de los lugares únicos y buscar interconexiones o interrelaciones entre dos o más escenarios en que la persona participa activamente. Por ejemplo las relaciones entre el hogar, el colegio y los amigos del vecindario. El que un niño aprenda a leer depende tanto de cómo le enseñan a leer, como de las relaciones entre el alumno y la escuela. Este vendría a ser el mesosistema, que no es otra cosa que un sistema de microsistemas.

El tercer punto del ambiente ecológico nos lleva a un punto más lejano y suscita la idea que el desarrollo de la persona está profundamente afectado por eventos que ocurren en lugares en que la persona ni siquiera se encuentra presente, por ejemplo el trabajo de los padres o una huelga de maestros. Este sería el exosistema. En este caso la persona en desarrollo no es un participante activo.

Por último el macrosistema se refiere a las consistencias, en la forma y contenido de sistemas de orden inferior (micro-meso y exo) que existen o que pueden existir dentro de una subcultura o cultura como conjunto, acompañado con sistema de creencias o ideologías que subyacen esas consistencias. En Lima las casas, las tiendas, etc. etc. funcionan de modo 
parecido y diferentemente que en París, Rabat, Pekín o Santiago. Lugares como casas, calles u oficinas tienden a ser muy parecidos, mientras que entre culturas son diferentes. Es como si existiera al interior de cada sociedad un proyecto para la organización de cada tipo de escenario. Este proyecto puede ser cambiado, lo que puede llevar a que el escenario en la sociedad pueda alterarse y producir cambios en la conducta y el desarrollo. Por ejemplo, una crisis económica severa en una sociedad puede tener un impacto negativo o positivo en el desarrollo posterior del niño, dependiendo de la edad del nińo en el momento en que la familia sufrió la presión económica. Esto seria el macrosistema.

El punto central y fundamental es que el desarrollo no se da en el vacío. Este siempre está inserto en un lugar y se expresa a través de conductas en un contexto ambiental particular. El desarrollo implica una reorganización en las características de las personas que tienen alguna continuidad a través del tiempo y del espacio. Asimismo, los cambios que se dan en el desarrollo ocurren paralelamente en dos dominios, aquellos de la percepción y de la acción. Cada uno de estos dominios tiene una estructura que es isomórfica con los cuatro niveles del ambiente ecológico.

Otro punto importante que vale la pena destacar, sobre todo para los países en vías de desarrollo, son los efectos que tienen ciertas variables ambientales en el desarrollo. Esto permitiría llevar a cabo intervenciones cuando los ambientes tienen influencias negativas. Un pionero en este campo es Pollitt $(1974,1991)$ quien destaca la importancia de la nutrición en el funcionamiento intelectual. Las intervenciones adecuadas permitirán que los efectos negativos en el rendimiento intelectual sean reversibles (Pollitt, 1991).

Los trabajos realizados en el campo de la psicología cognitiva (Bransford, Golman y Vye, 1991) destacan la naturaleza social del conocimiento y su importancia para el desarrollo de las habilidades básicas de pensamiento. Estos trabajos incluyen, no sólo la participación del colegio en el desarrollo del pensamiento, sino también la de los padres. Una experiencia, en este sentido que tuvo mucho éxito fue la de Machado, ex-Ministro de la Inteligencia de Venezuela, quien basándose en los trabajos de Feuerstein desarrolló un programa para estimular el desarrollo del pensamiento en los nińos. Lamentablemente esta experiencia fue interrumpida. 
Un aspecto fundamental de la psicología del desarrollo es que hay que estudiar al individuo en su ecología presente. Si tomamos en cuenta el caso del Perú, un país con variaciones enormes entre los contextos y las regiones, con diferencias socioeconómicas bastante marcadas entre sus habitantes, el ambiente en que vive el individuo es fundamental para poder comprenderlo a cabalidad. Esto lleva al concepto de validez ecológica que se refiere hasta qué punto el ambiente en que viven los sujetos de una investigación científica tienen las propiedades que el investigador supone $o$ asume que tienen.

\section{Conclusiones}

- Los psicólogos del desarrollo deben preocuparse por las diferencias individuales en el desarrollo bajo condiciones de crianza similares, así como del nivel promedio de desarrollo expresado bajo condiciones diferentes o contrastantes. Una posición evolutiva incorpora ambas perspectivas, porque los individuos varían genéticamente en sus respuestas a diferentes condiciones ambientales.

- Esto no nos debe llevar a una posición pesimista y pasiva. como dice Scarr, irónicamente la mayor contribución de los estudios genéticos de la conducta es clarificar el impacto de las diferencias ambientales en el desarrollo humano.

- El desarrollo normal se da en una variabilidad muy amplia de ambientes humanos, pero no en aquellos en los que faltan las condiciones "promedio esperables". Un ambiente normal incluye padres adultos protectores y un ambiente social en el cual socializarse.

- Un mayor conocimiento de los diferentes contextos en que se desenvuelve el niño es importante para llegar a comprender mejor su desarrollo. Es por ello que deberíamos tratar de definir el "Ambiente Promedio Esperable" en nuestro medio y a partir de qué momento el ambiente se torna peligroso para el desarrollo del individuo.

- Se podría hacer un mejor trabajo si supiéramos qué cambios en el ambiente tienen un impacto y cuáles no. Esto permitiría invertir nuestros recursos en cambiar aquellas circunstancias que claramente 
tienen efectos perniciosos en el desarrollo. Esto llevaría, así mismo, a predicciones realistas acerca de la eficacia de las intervenciones, si tenemos en cuenta las diferencias individuales en respuesta a estos cambios. Es dentro del mejor interés de los niños tener conocimiento acerca de sus diferencias y de su desarrollo promedio.

- Las investigaciones y la interpretación de los resultados de las investigaciones deben tener una validez ecológica. Hasta qué punto el ambiente en que viven los individuos de una investigación científica tienen las propiedades que el investigador supone o asume que tiene.

- Sólo una vez que tengamos un conocimiento real de las posibilidades del desarrollo del individuo, así como de los diferentes ambientes y sus efectos, es que podremos desarrollar programas de prevención adecuados para evitar los efectos negativos en el desarrollo del individuo.

\section{Referencias}

Biehler, R.F.(1980). Introducción al Desarrollo del Niño. México: Editorial Diana.

Bransford, J.D. , Goldman, S.R.y Vye, N. (1991). Making a Difference in Peoples's Abilities to Think: Reflections on a Decade of Work and Some Hopes for the Future. En Okagaki, L. y Sternberg, R. (Eds) Directors of Development: influences on the development of children's thinking. New Jersey: Lawrence Erlbaum

Bronfenbrenner, U. (1979). The Ecology of Human Development. Cambridge: Harvard University Press.

Bronfenbrenner, U. (1986). Ecology of the Family as a Context for Human Development: Research Perspectives. Developmental Psychology 22(6), 723-742.

González, R. (1993). Perfil del Niño Peruano. (Documento de Trabajo) Ministerio de Educación.

Gordon, E. W. y Armour-Thomas, E. (1991). Culture and Cognitive Development. En Okagaki, L. y Sternberg, R. (Eds) Directors of Development: influences on the development of children's thinking. New Jersey: Lawrence Erlbaum 
Hoffman, L., Paris, S. Hall, E. y Schell,R (1988). Developmental Psychology Today. Nueva York: McGraw Hill Publishing Company.

Majluf, A. (1993). Marginalidad, inteligencia y rendimiento escolar. Lima: Brandon Enterpise.

Okagaki, L. y Sternberg, R. (1991). Cultural and Parental Influences on Cognitive Development. En Okagaki, L. y Sternberg, R. (Eds) Directors of Development: influences on the development of children's thinking.New Jersey: Lawrence Erlbaum

Panez, R. (1989). Bajo el sol de la infancia: creencias y tradiciones en la crianza limeña. Lima: CONCYTEC.

Pollitt, E. (1974). Desnutrición, pobreza e inteligencia. Lima: Retablo de Papel.

Pollitt, E. (1991). Efectos de la deficiencia de hierro en el funcionamiento intelectual. Revista de Psicologia, 9, 123-159.

Scarr, S. (1992). Developmental Theories for the 1990's: Developmental and Individual Differences. Child Development 63, 1-19.

Scarr, S. and Ricciuti, A. (1991). What effects do parents have on their children? En Okagaki, L. y Sternberg, R. (Eds) Directors of Development: influences on the development of children's thinking. New Jersey: Lawrence Erlbaum

Scarr, S. y Weinberg (1983). The Minnesota adoption studies: Genetic differences and malleability. Child Development, 54, 260-267.

Thorne, C., Delgado, A. y Escurra, M. (1993). Investigaciones con Pruebas Psicológicas en el Perú. Comunicación presentada en el XXIV Congreso Interamericano de Psicología. Santiago: 4 al 9 de Julio. 